\title{
Erratum to: Subacute steroid-induced paraparesis: surgical treatment of a devastating "invisible" side effect
}

M. Javad Mirzayan • Thomas Goessling •

Tobias Huefner $\cdot$ Joachim K. Krauss

Published online: 10 May 2012

(C) Springer-Verlag 2012

Erratum to: Eur Spine J

DOI 10.1007/s00586-012-2185-3

There was an error in the author's name of the article.

The correct name is M. Javad Mirzayan.

The online version of the original article can be found under doi:10.1007/s00586-012-2185-3.

M. J. Mirzayan $(\bowtie) \cdot J$. K. Krauss

Department of Neurosurgery, Medical School Hannover,

Carl-Neuberg-Str. 1, 30625 Hannover, Germany

e-mail: mirzayan@hotmail.com

T. Goessling · T. Huefner

Department of Traumatology, Medical School Hannover,

Hannover, Germany 